\title{
Uncertainty of Thermographic Temperature Measurement with an Additional close-up Lens
}

\author{
Krzysztof Dziarski ${ }^{1}$, Arkadiusz Hulewicz ${ }^{2}$ \\ ${ }^{I}$ Institute of Electric Power Engineering, Poznan University of Technology, Piotrowo 3A, 60-965 Poznan, Poland, \\ Krzysztof.Dziarski@put.poznan.pl \\ ${ }^{2}$ Institute of Electrical Engineering and Electronics, Poznan University of Technology, Piotrowo 3A, 60-965 Poznan, Poland
}

\begin{abstract}
The thermographic temperature measurement is burdened with uncertainty. This non-contact temperature measurement method makes it possible to measure the temperature of the electrical device under load. When the observed object is small (a few square millimeters) the spatial resolution of the thermographic cameras is often insufficient. In this case, the use of the additional macro lens is needed. After using an additional lens, the uncertainty of the thermographic measurement is different from the uncertainty of thermographic measurement without an additional lens. The values of the uncertainty contributions depend on the conditions during the measurement and the used methodology. The authors constructed an uncertainty budget of thermographic temperature measurement with an additional macro lens, based on EA-4/02 (European Accreditation publications). The uncertainty contributions were also calculated. On the basis of the calculated values of the uncertainty contributions, it was determined which factor had the greatest impact on the value of the thermographic temperature measurement with an additional lens.
\end{abstract}

Keywords: Type B evaluation of uncertainty, thermography, thermographic camera, electronics, uncertainty contributions.

\section{INTRODUCTION}

Each measurement is burdened with an uncertainty [1]. According to the definition, the uncertainty of measurement is a parametric (or parameters) characterizing how well the (essentially unique) true value of the measurand is believed to be known. The older definition specifies uncertainty as a non-negative parameter characterizing the dispersion of the quantity values being attributed to a measurand, based on the information used [2], [3]. The temperature measurement is also burdened with uncertainty [4].

Information about the temperature of the tested electronic component is important diagnostic information. It allows to answer the question: how much can a component be loaded so that the temperature of the component is not too high. Cyclic measurement of the temperature of the component allows to detect the increase in temperature preceding the damage of the component. Long-term operation of the component with too high temperature shortens its exploitation time [5].

Temperature of the electronic component case may be measured by thermography. This non-contact method has a lot of advantages. It allows to perform the measurement of the element temperature under load. Lack of contact between the component and the temperature sensor located in the thermal imaging camera makes it a safe method. An additional advantage is the possibility of recording the temperature distribution on a surface of an electronic component case [6], [7].

The value of uncertainty of a thermographic temperature measurement depends on the conditions during measurement, the parameters of equipment which was used and the technique of the performed measurement. The values of contributions of uncertainty will be also different. Values of the uncertainty contributions will be different in the case, when distance $d$ between thermographic camera lens and the observed object is large (in the range of kilometers), and values of the uncertainty contributions will be different in the case, when the $d$ is small (in the range of millimeters) [8].

During the evaluation of the thermographic measurement uncertainty, the range of factors which affect the result of the thermographic measurement of the temperature should be determined. These factors are the value of the emission factor [9], the temperature of the reflection [10], the distance between the camera lens and the observed object [11], [12], the ambient temperature [13], the temperature of the external optical system [14], the transmission of the external optical system [15], [16], and relative humidity [17]. These are the factors whose contribution to the uncertainty budget can be easily determined on the basis of measurements or available literature [18], [19]. 
During the thermographic measurements of the temperature of the electronic components, the additional macro lenses are often used. It is needed when the thermographic camera's sensor array does not have sufficient spatial resolution. In this case, the use of an additional lens enables the registration of temperature distributions in cases of small cases such as SMD (Surface Mounted Devices) and BGA (Ball Grid Array). During thermographic temperature measurements with an additional macro lens, it is important to select a precise $d=33$ millimeters [20]. In this case, during the evaluation of the uncertainty of the thermographic measurement of the temperature, two additional factors must be taken into account: the temperature of the additional macro lens $\vartheta_{l}$ and the transmittance of the additional macro lens $\tau_{l}$ [8].

Knowledge of the value of contribution of components in the uncertainty of thermographic measurement of the temperature provides knowledge about the effect of individual factors on the result of a thermographic temperature measurement $\vartheta_{\text {cam }}$ and to which factor's compensation should be paid special attention.

As a result of the analysis of the available literature, no publications on thermographic temperature measurement with additional macro lens were found. For this reason, the studies were conducted to determine the contribution rate of participation related to the occurrence of individual factors in the uncertainty budget of the thermographic temperature measurement performed with an additional macro lens.

\section{DETERMINATION OF UNCERTAINTY}

\subsection{Measurement system}

The main part of the made stand was a stand with a Flir E50 thermal imaging camera (Flir, Wilsonville, Oregon, USA) [21]. The camera was equipped with an additional macro Close-up 2x lens (Flir, Wilsonville, Oregon, USA) [22]. The used lens allowed for spatial resolution (IFOV) of $67 \mu \mathrm{m}$. Thanks to the applied linear guide with engine 57H56H3004A [23], it was possible to change $d$ with a step equal to $0.1 \mathrm{~mm}$.

Under the lens, at a distance of $d=33 \mathrm{~mm}$, the object under observation was placed, which was a Pt1000 sensor with a known value of resistance. Diameter of the sensor's case was equal to $3 \mathrm{~mm}$ and the length of the sensor's case was equal to $6 \mathrm{~mm}$. The sensor was placed on an aluminum table measuring $2 \mathrm{~cm} \times 3 \mathrm{~cm}$. In order to minimize the IR radiation reflections inside the chamber, the table was painted with black paint. Due to the large (compared to the dimensions of Pt1000) dimensions of the table, a polyurethane foam was placed between the table and the observed sensor. In this way the influence of the thermal capacity of the table on the measured value of Pt1000 temperature was eliminated.

The constructed stand with the camera and the object under observation was placed in a chamber with external dimensions of $40 \mathrm{~cm} \times 30 \mathrm{~cm} \times 30 \mathrm{~cm}$ made of plexiglass. The internal sides of the chamber walls were lined with black foam made of polyurethane. Polyurethane foam is characterized by high emissivity factor $\varepsilon=0.95$ [24] and low reflectance factor $\rho$. It enabled the optical isolation of the chamber's interior and the minimization of IR radiation reflections inside the chamber.

Thermographic camera was connected with a laptop by USB interface. The laptop was put outside the chamber. Flir Tools software was installed on this laptop. The settings of the thermographic camera, which was used, had been changed in Flir Tools Software.

The $d$ value was changed by selecting the appropriate value on the HMI touch panel. The touch panel was connected to a Siemens Simatic S7-1200 controller in the CPU 1214 DC/DC/DC version, designated 6ES72141BG40-0XB0 (Siemens AG, Munich, Germany) [25]. In turn, the PLC was connected to the stepper motor. The constructed measurement system is shown in Fig.1. The block diagram is shown in Fig. 2 .

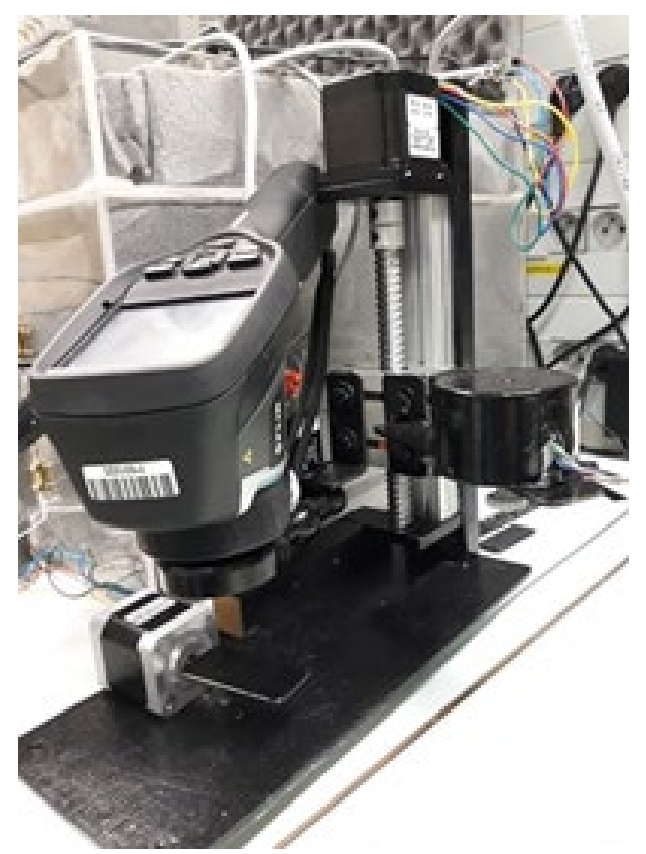

Fig.1. The view of the constructed measurement system with thermographic camera and additional lens.

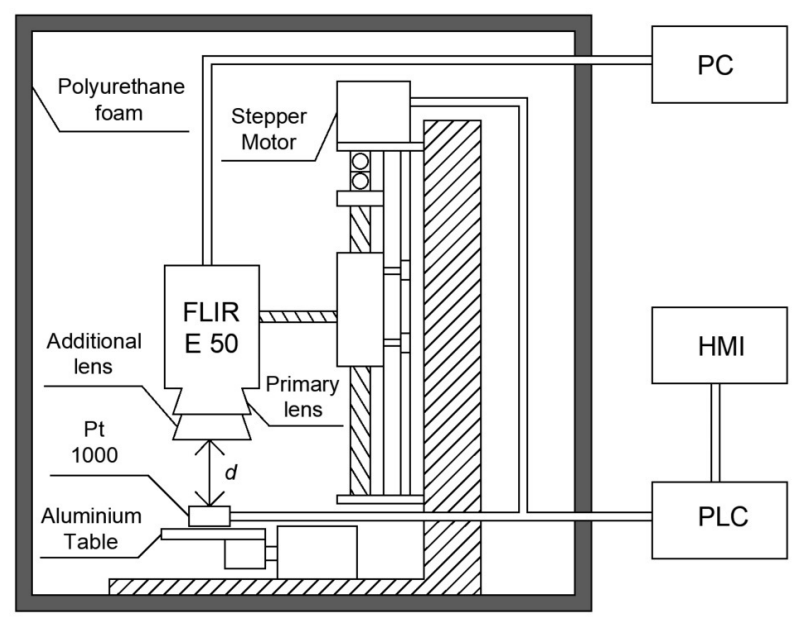

Fig.2. The block diagram of the measurement system. 


\subsection{Components of IR radiation}

In the present case, the infrared radiation, which reaches to the thermographic camera lens, consists of four parts [8]:

- The IR radiation from the surroundings, which was reflected from the observed object (aluminum block) $I R_{\text {refl }}$,

- $\quad$ The IR radiation emitted by the observed object $I R_{o b j}$,

- The IR radiation emitted by air between thermographic camera lens and the observed object $I R_{a}$,

- The IR radiation emitted by additional close-up $2 \mathrm{x}$ lens $I R_{l}$.

All of the infrared radiation components, which were mentioned above, may be described by equations (1-4).

$$
\begin{gathered}
I R_{r e f l}=(1-\varepsilon) \cdot W_{r e f l} \cdot \tau_{a} \cdot \tau_{l} \\
I R_{o b j}=\varepsilon \cdot W_{o b j} \cdot \tau_{a} \cdot \tau_{l} \\
I R_{a}=\left(1-\tau_{a}\right) \cdot W_{a} \cdot \tau_{l} \\
I R_{l}=\left(1-\tau_{l}\right) \cdot W_{l}
\end{gathered}
$$

where: $\varepsilon$ - emissivity factor of the observed object, $W_{\text {refl }}$ the ambient radiation reflected from the observed object, $\tau_{a}$ the transmittance factor of ambient (air between thermographic camera lens and the observed object), $\tau_{l}$ - the transmittance factor of the additional thermographic camera lens, $W_{o b j}$ - the radiation emitted by the observed object, $W_{a}$ the radiation emitted by the ambient, $W_{l}$ - the radiation emitted by the additional thermographic camera lens.

The components of the IR radiation are shown in Fig.3.

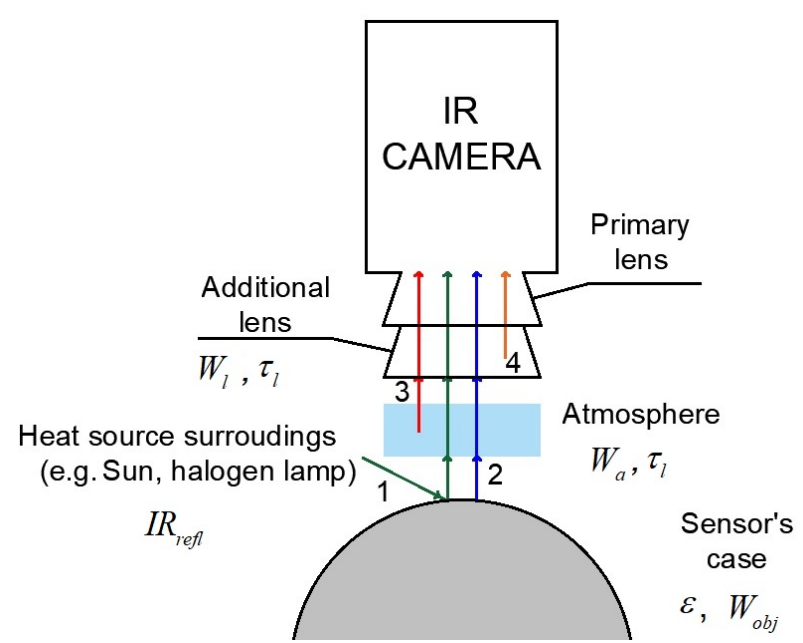

Fig.3. Components of IR radiation which reach the thermographic camera lens: 1) IR radiation reflected from the observed object, 2) IR radiation emitted by the observed object, 3) IR radiation emitted by air, 4) IR radiation emitted by the additional lens.
After adding the equations (1-4), fulfilling the StefanBoltzmann law and carrying out the transformations, the equation describing the temperature of the observed object $\vartheta_{o b j}$ on the basis of the total infrared radiation reaching the thermal camera lens takes the form of equation 5.

$$
\begin{aligned}
& \vartheta_{o b j}=\sqrt[4]{\frac{A}{\varepsilon \cdot \tau_{a} \cdot \sigma \cdot \tau_{l}}} \\
& A=W_{t o t}-(1-\varepsilon) \cdot \tau_{a} \cdot \sigma \cdot \vartheta_{r e f l}^{4} \cdot \tau_{l}-\left(1-\tau_{a}\right) \\
& \cdot \sigma \cdot \vartheta_{a}^{4} \cdot \tau_{l}-\left(1-\tau_{l}\right) \cdot \sigma \cdot \vartheta_{l}^{4}
\end{aligned}
$$

where: $\sigma$ is the Boltzmann constant equal to $5.67 \mathrm{~cm} \times 10^{-8} \mathrm{~W} /\left(\mathrm{m}^{2} \cdot \mathrm{K}^{4}\right), \quad W_{\text {tot }}-$ the total IR radiation reaching the camera lens, $\vartheta_{a}-$ the temperature of ambient, $\vartheta_{\text {refl }}-$ the temperature reflected from the observed object, $\vartheta_{l}-$ the temperature of additional macro lens [26].

The value $\tau_{a}$ can be determined by means of the formula (6). To determine the value $\tau_{a}$, first the humidity value $\omega$ should be determined. This can be done by means of formula (7)

$$
\begin{gathered}
\tau_{a}(d, \omega)=K_{a} \cdot \exp \left[-\sqrt{d} \cdot\left(\alpha_{1}+\beta_{1} \sqrt{\omega}\right)\right]+ \\
+\left(1-K_{a}\right) \cdot \exp \left[-\sqrt{d} \cdot\left(\alpha_{2}+\beta_{2} \sqrt{\omega}\right)\right] \\
\omega\left(\omega_{\%}, \vartheta_{a}\right)=\omega_{\%} \cdot \exp \left(h_{1}+h_{2} \cdot \vartheta_{a}+\right. \\
\left.+h_{3} \cdot \vartheta_{a}^{2}+h_{4} \cdot \vartheta_{a}^{3}\right)
\end{gathered}
$$

where: $\omega$ is the factor indicating the amount of water vapor in the atmosphere, $\omega \%$ is relative humidity, $K_{a t m}=1.9$ is the atmosphere damping factor, $\alpha_{1}$ and $\alpha_{2}$ are damping factors for an atmosphere without water vapor, $\beta_{1}$ and $\beta_{2}$ are damping factors for water vapor $h_{1}=1.5587 h_{2}=6.939 \cdot 10^{-2}$, $h_{3}=-2.7816 \cdot 10^{-4}$, and $h_{4}=6.845 \cdot 10^{-7}$ [27].

\subsection{Method of evaluation of uncertainty}

In order to determine the standard uncertainty of the performed thermographic temperature measurement, the method of determining the uncertainty of type B was selected. This method was chosen due to the small number of measurements and the changing conditions during the measurements. Type B standard uncertainty assessment is a method of assessing uncertainty other than the statistical analysis of a series of observations. In this case the evaluation of the standard uncertainty is based on some other scientific knowledge [28]. In the case of this method it is necessary to construct the uncertainty budget. The calculation of contributions of uncertainty is also needed. The contributions of uncertainty are the part of a constructed uncertainty budget.

In order to determine the contributions of individual factors in the standard uncertainty of a thermographic temperature measurement with additional lens $u\left(\vartheta_{o b j}\right)$, the 
scope of values of components listed on the right of equations (5)-(7) was determined. The limits of scopes of $\tau_{a}$ $(-)$ and $W_{\text {tot }}$ (in $\mathrm{W} / \mathrm{m} 2$ ) were determined on the basis of simulation works in Matlab software, during which equations (6) and (7) were used. As the $\tau_{l}(-)$ scope, the widest material transmittance scope, which is used for manufacturing thermal camera lenses within the LWIR (Long Wave InfraRed) scope, was selected [8]. The scopes of other factors included in equations (5)-(7) were determined on the basis of experimental work during which a resistance temperature sensor with a known temperature value (which has been mentioned in section 2.1), was being applied.

The limit of scopes of $\vartheta_{\text {refl }}$ was determined on the basis of the experimental work too. For this reason, the aluminum table with Pt1000 sensor was changed to an aluminum block with dimensions equal to $16 \mathrm{~mm} \times 16 \mathrm{~mm} \times 45 \mathrm{~mm}$ with a hollow hemisphere. The radius of this hemisphere equals $5 \mathrm{~mm}$. The measured point was set at the bottom of the hemisphere. During the measurement of the $\vartheta_{\text {refl }}$ value, the $\varepsilon$ $(-)$ and $d$ (in $\mathrm{mm}$ ) compensation was turned off (the setting $\varepsilon=1$ and the setting $d=0$ ). The value of the temperature read from the recorded thermogram was assumed as the measured reflected temperature value.

The equal probability of values occurring in the designated ranges made it possible to assign a rectangular probability distribution to all quantities. Assigning the variables from equations (5)-(7) of a rectangular probability distribution made it possible to determine the estimated value related to a given factor using equation 8 [28].

$$
x_{i}=\frac{1}{2}\left(a_{+}+a_{-}\right)
$$

where: $a_{+}$- the upper scope limit, $a_{-}$- the lower scope limit, $x_{i}$ - the obtained estimate.

The standard uncertainty $u\left(x_{i}\right)$ was determined as the root of the variance. The uncertainty was obtained using equation 9 [20].

$$
u\left(x_{i}\right)=\sqrt{\frac{1}{12}\left(a_{+}-a_{-}\right)^{2}}
$$

In order to determine the contribution to the uncertainty $u_{i}(y)$, the value of $u\left(x_{i}\right)$ was multiplied by the sensitivity factor $c$. The $c$ describes the extent to which the estimate of the output $y$ is influenced by changes in the estimate of the input $x_{i}$. The value of $c$ represents the value of first derivative of equations (5)-(7) in relation to the variable representing the factor in question [28]. Values of $c$ have been calculated by using the numerical method. For this reason, the output estimate $y$ due to a corresponding change in the input estimate $x_{i}$ of $+u\left(x_{i}\right)$ and $-u\left(x_{i}\right)$ was calculated. The values for $c$ were obtained by dividing the resulting difference in $y$ by $2 u\left(x_{i}\right)$.

The standard uncertainty of output quantities $u(y)$ was determined as the root of the sum of squares of values of individual contributions. The expanded uncertainty $U(y)$ was determined by multiplying $u(y)$ by the coverage factor $k$. The $k$ is a number greater than one by which the combined standard measurement uncertainty is multiplied to obtain the expanded measurement uncertainty [28]. During these studies, the value of $k$ was equal to 2 .

\section{THE UNCERTAINTY BUDGET}

Two other uncertainty budgets had to be constructed before constructing the uncertainty budget for a thermographic measurement with an additional lens. At the beginning, on the basis of equation 7 , the uncertainty budget for $\omega$ was determined. The budget is presented in Table 1. Evaluation of uncertainty budget in tables can be seen in other articles [29], [30].

Table 1. Uncertainty budget for $\omega$.

\begin{tabular}{|l|c|c|l|l|c|}
\hline $\begin{array}{c}\text { Sym } \\
\boldsymbol{b o l} \\
\boldsymbol{X}_{\boldsymbol{i}}\end{array}$ & $\begin{array}{c}\text { Estimate } \\
\text { of } \\
\text { quantity } \\
\boldsymbol{x}_{\boldsymbol{i}}\end{array}$ & $\begin{array}{c}\text { Standard } \\
\text { Uncertain } \\
\text { ty } \\
\boldsymbol{u}\left(\boldsymbol{x}_{\boldsymbol{i}}\right)\end{array}$ & $\begin{array}{c}\text { Probabi } \\
\text { lity } \\
\text { distribu } \\
\text { tion }\end{array}$ & $\begin{array}{c}\text { Sensitiv } \\
\text { ity } \\
\text { Factor } \\
\boldsymbol{c}_{\boldsymbol{i}}\end{array}$ & $\begin{array}{c}\text { Uncert } \\
\text { ainty } \\
\text { contri } \\
\text { bution } \\
\boldsymbol{u}_{\boldsymbol{i}}(\boldsymbol{y})\end{array}$ \\
\hline$\vartheta_{a}$ & $26.5\left[{ }^{\circ} \mathrm{C}\right]$ & $4.90\left[{ }^{\circ} \mathrm{C}\right]$ & $\begin{array}{l}\text { rectangu } \\
\text { lar }\end{array}$ & 0.62 & $3.04[-]$ \\
\hline$\omega \%$ & $44.5[\%]$ & $17.32[\%]$ & $\begin{array}{l}\text { rectangu } \\
\text { lar }\end{array}$ & 0.25 & $4.33[-]$ \\
\hline$\omega$ & $13.93[-]$ & & & & $5.29[-]$ \\
\hline
\end{tabular}

Similarly, on the basis of equation (6), the uncertainty budget for $\tau_{a}$ was determined. The uncertainty budget for $\tau_{a}$ is presented in Table 2 .

Table 2. Uncertainty budget for $\tau_{a}$, superior to the budget for $\omega$.

\begin{tabular}{|c|l|l|l|c|c|}
\hline $\begin{array}{c}\text { Sym } \\
\boldsymbol{b o l} \\
\boldsymbol{X}_{\boldsymbol{i}}\end{array}$ & $\begin{array}{c}\text { Estimat } \\
\text { e of } \\
\text { quantity }\end{array}$ & $\begin{array}{c}\text { Standard } \\
\text { Uncertai } \\
\text { nty }\end{array}$ & $\begin{array}{c}\text { Proba } \\
\text { bility } \\
\text { distrib } \\
\text { ution }\end{array}$ & $\begin{array}{c}\text { Sensitivity } \\
\text { Factor }\end{array}$ & $\begin{array}{c}\text { Uncert } \\
\text { ainty } \\
\text { contrib } \\
\text { ution }\end{array}$ \\
& $\boldsymbol{x}_{\boldsymbol{i}}$ & $\boldsymbol{u}\left(\boldsymbol{x}_{\boldsymbol{i}}\right)$ & & & $\boldsymbol{u}_{\boldsymbol{i}}(\boldsymbol{y})$ \\
\hline$\omega$ & 13.93 & 5.29 & normal & $-3.78^{\cdot} \cdot 10^{-5}$ & $\begin{array}{l}-0.003 \\
{[-]}\end{array}$ \\
\hline$d$ & {$[-]$} & {$[-]$} & & & -0.0007 \\
& 0.033 & 0.0057 & rectang & -0.0204 & {$[-]$} \\
\hline$\tau_{a}$ & 0.9987 & & ular & & 0.0010 \\
& {$[-]$} & & & & \\
\hline
\end{tabular}

The final uncertainty budget done for the quantity $\vartheta_{o b j}$ is presented in Table 3 .

Estimates of $\omega$ and $\tau_{a}$ were determined using equation (8). As the $\omega$ and $\tau_{a}$ variability scope, the highest and lowest possible values were assumed, depending on values of input quantities in equations (6) and (7). By virtue of the Central Limit Theorem, both quantities are assigned a normal probability distribution.

The limits of the $W_{\text {tot }}$ scope were performed on the basis of the simulation work. It was found that $W_{\text {tot }}$ scope was between $0.1669 \mathrm{~W} / \mathrm{m}-0.1439 \mathrm{~W} / \mathrm{m}$. On the basis of the 
experimental work and data from literature, it was found that the limits of $\vartheta_{\text {refl }}$ scopes are: $25^{\circ} \mathrm{C}-35^{\circ} \mathrm{C}, \vartheta_{a}$ : $18{ }^{\circ} \mathrm{C}$ $35{ }^{\circ} \mathrm{C}, \tau_{l}: 0.9-1, \omega \%: 40 \%-60 \%, \varepsilon: 0.95-0.98$, and scope $d$ varies from $20 \mathrm{~mm}-50 \mathrm{~mm}$. In addition, it was assumed that $\vartheta_{a}=\vartheta_{l}$. Expanded uncertainty value $U(y)$ was obtained by multiplying the value of $u(y)=0.55^{\circ} \mathrm{C}$ by the coverage factor $k=2$. The value of expanded uncertainty $U\left(\vartheta_{o b j}\right)$ was $1.11^{\circ} \mathrm{C}$ for $\vartheta_{o b j}=41.36^{\circ} \mathrm{C}$.

Table 3. Primary uncertainty budget for the quantity $\vartheta_{o b j}$.

\begin{tabular}{|c|c|c|c|c|c|}
\hline $\begin{array}{c}\text { Sym } \\
\text { bol } \\
X_{i}\end{array}$ & $\begin{array}{c}\text { Estimate } \\
\text { of } \\
\text { quantity } \\
x_{i}\end{array}$ & $\begin{array}{c}\text { Standa } \\
\text { rd } \\
\text { Uncert } \\
\text { ainty } \\
u\left(x_{i}\right)\end{array}$ & $\begin{array}{c}\text { Proba } \\
\text { bility } \\
\text { distrib } \\
\text { ution }\end{array}$ & $\begin{array}{c}\text { Sensitivi } \\
\text { ty } \\
\text { Factor } \\
c_{i}\end{array}$ & $\begin{array}{c}\text { Uncerta } \\
\text { inty } \\
\text { contribu } \\
\text { tion } \\
u_{i}(y) \\
\end{array}$ \\
\hline$\tau_{a}$ & $\begin{array}{l}0.9987 \\
{[-]}\end{array}$ & $\begin{array}{l}0.0010 \\
{[-]}\end{array}$ & normal & 0.4488 & $\begin{array}{l}0.0004 \\
{\left[{ }^{\circ} \mathrm{C}\right]}\end{array}$ \\
\hline$W_{t o t}$ & $\begin{array}{l}0.1554 \\
{[\mathrm{~W} / \mathrm{m}]}\end{array}$ & $\begin{array}{l}0.0066 \\
{[\mathrm{~W} / \mathrm{m}]}\end{array}$ & $\begin{array}{l}\text { rectan } \\
\text { gular }\end{array}$ & 67.7701 & $\begin{array}{l}0.4472 \\
{\left[{ }^{\circ} \mathrm{C}\right]}\end{array}$ \\
\hline$\varepsilon$ & $\begin{array}{l}0.9700 \\
{[-]}\end{array}$ & $\begin{array}{l}0.0086 \\
{[-]}\end{array}$ & $\begin{array}{l}\text { rectan } \\
\text { gular }\end{array}$ & -7.6450 & $\begin{array}{l}-0.0657 \\
{\left[{ }^{\circ} \mathrm{C}\right]} \\
\end{array}$ \\
\hline$\vartheta_{\text {refl }}$ & $\begin{array}{l}30 \\
{\left[{ }^{\circ} \mathrm{C}\right]}\end{array}$ & $\begin{array}{l}2.8868 \\
{\left[{ }^{\circ} \mathrm{C}\right]}\end{array}$ & $\begin{array}{l}\text { rectan } \\
\text { gular }\end{array}$ & 0.0119 & $\begin{array}{l}0.0344 \\
{\left[{ }^{\circ} \mathrm{C}\right]}\end{array}$ \\
\hline$\tau_{l}$ & $\begin{array}{l}0.9500 \\
{[-]}\end{array}$ & $\begin{array}{l}0.0289 \\
{[-]}\end{array}$ & $\begin{array}{l}\text { rectan } \\
\text { gular }\end{array}$ & -10.3189 & $\begin{array}{l}0.2982 \\
{\left[{ }^{\circ} \mathrm{C}\right]}\end{array}$ \\
\hline$\vartheta_{a}$ & $\begin{array}{l}26.500 \\
{\left[{ }^{\circ} \mathrm{C}\right]}\end{array}$ & $\begin{array}{l}4.9000 \\
{\left[{ }^{\circ} \mathrm{C}\right]}\end{array}$ & $\begin{array}{l}\text { rectan } \\
\text { gular }\end{array}$ & -0.0151 & $\begin{array}{l}-0.0740 \\
{\left[{ }^{\circ} \mathrm{C}\right]}\end{array}$ \\
\hline$\vartheta_{l}$ & $\begin{array}{l}26.500 \\
{\left[{ }^{\circ} \mathrm{C}\right]}\end{array}$ & $\begin{array}{l}4.9000 \\
{\left[{ }^{\circ} \mathrm{C}\right]}\end{array}$ & $\begin{array}{l}\text { rectan } \\
\text { gular }\end{array}$ & -0.0151 & $\begin{array}{l}-0.0740 \\
{\left[{ }^{\circ} \mathrm{C}\right]}\end{array}$ \\
\hline$\vartheta_{o b j}$ & $\begin{array}{l}41.357 \\
{\left[{ }^{\circ} \mathrm{C}\right]}\end{array}$ & $\begin{array}{l}0.0010 \\
{\left[{ }^{\circ} \mathrm{C}\right]}\end{array}$ & & & $\begin{array}{l}0.5525 \\
{\left[{ }^{\circ} \mathrm{C}\right]}\end{array}$ \\
\hline
\end{tabular}

\section{CONCLUSION}

When analyzing the contribution of uncertainty components of a thermography temperature measurement with the use of an additional macro lens (Table 1.- Table 3.), it can be noticed that the humidity has little effect on the temperature measurement error. The temperature and transmittance of additional lens largely influence the uncertainty of temperature measurement. For this reason, the thermographic camera should be calibrated together with the additional lens. In case of use of a thermographic camera with uncooled detectors (for example with microbolometers), the temperature of the additional lens should be close to the air temperature which is near this additional lens. It is worth noting that it is often impossible to freely influence the value of these quantities.

Other factors that largely influence the value of thermography measurement error with the use of a macro lens include the correct selection of the emissivity factor and the reflected temperature. For this reason, before performing the thermography temperature measurement with the use of a macro lens, special attention should be paid to the correct selection of the emissivity factor and to the compensation of the reflected radiation.

It is worth noting that the skill of analyzing the uncertainty components may also be helpful in planning measurements of other quantities.

\section{REFERENCES}

[1] Ferreira, R.A.M., Silva, B.P.A, Teixeira, G.G.D., Andrade, R.M., Porto, M.P. (2019). Uncertainty analysis applied to electrical components diagnosis by infrared thermography. Measurement, 132, 263-271.

[2] Grégis, F. (2019). On the meaning of measurement uncertainty. Measurement, 133 (5), 41-46.

[3] Varba, I., Palencar, R., Hadzistevic, M., Strbac, B., Spasic-Jokic, V., Hodolic, J. (2011). Compact vibration measuring system for in-vehicle applications. Measurement Science Review, 11 (5), 154-159.

[4] Palenčár, R., Sopkuliak, P., Palenčár, J., Duriš, S., Suroviak, E., Halaj, M. (2017). Application of Monte Carlo method for evaluation of uncertainties of ITS-90 by standard platinum resistance thermometer. Measurement Science Review, 3 (17), 108-116.

[5] Usamentiaga, R., Fernandez, M.A., Villan, A.F., Carus, J.L. (2018). Temperature monitoring for electrical substations using infrared thermography: Architecture for industrial internet of things. IEEE Transactions on Industrial Informatics, 14 (12), 56675677.

[6] Orlov, S.P., Girin, R.V., Uyutova, O.Y. (2018). Artificial neural network for technical diagnostics of control systems by thermography. In International Conference on Industrial Engineering, Applications and Manufacturing (ICIEAM). IEEE, 1-4.

[7] Kopec, M., Wiecek, B. (2018). Low-cost IR system for thermal characterization of electronic devices. Measurement Automation Monitoring, 64 (4), 103107.

[8] Dziarski, K., Hulewicz, A., Dombek, G. (2021). Lack of thermogram sharpness as component of thermographic temperature measurement uncertainty budget. Sensors, 21 (12), 4013-4023.

[9] Zaccara, Z., Edelman, J.B., Cardone, G. (2020). A general procedure for infrared thermography heat transfer measurements in hypersonic wind tunnels. International Journal of Heat and Mass Transfer, 163, 120419-120435.

[10] Altenburg, J.S., Straße, A., Gumenyuk, A., Meierhofer, C. (2020). In-situ monitoring of a laser metal deposition (LMD) process: Comparison of MWIR, SWIR and high-speed NIR thermography. Quantitative InfraRed Thermography Journal, doi: 10.1080/17686733.2020.1829889.

[11] Yoon, S.T., Park, J.C., Cho, Y.J. (2021). An experimental study on the evaluation of temperature uniformity on the surface of a blackbody using infrared cameras. Quantitative InfraRed Thermography Journal, doi: 10.1080/17686733.2021. 1877918.

[12] Muniz, P.R., Kalid, R.A., Cani, S.P., Magalhaes, R.S. (2014). Handy method to estimate uncertainty of temperature measurement by infrared thermography. Optical Engineering, 53, 7. 
[13] Schuss, C., Remes, K., Leppänen, K., Saarela, J., Fabritius, T., Eichberger, B., Rahkonen, T. (2020). Detecting defects in photovoltaic cells and panels with the help of time-resolved thermography under outdoor environmental conditions. In 2020 IEEE International Instrumentation and Measurement Technology Conference (I2MTC). IEEE, 1-6.

[14] Chakraborty, B., Billol, K.S. (2020). Processintegrated steel ladle monitoring, based on infrared imaging - a robust approach to avoid ladle breakout. Quantitative InfraRed Thermography Journal, 17 (3), 169-191.

[15] Tomoyuki, T. (2020). Coaxiality evaluation of coaxial imaging system with concentric silicon-glass hybrid lens for thermal and color imaging. Sensors, 20 (20), 5753-5772.

[16] Wollack, J.E., Cataldo, G., Miller, K.H., Quijada, A.M. (2020). Infrared properties of high-purity silicon. Optical Letters, 45 (17), 4935-4938.

[17] Singh, J., Arora, A.S. (2021). Effectiveness of active dynamic and passive thermography in the detection of maxillary sinusitis. Quantitative InfraRed Thermography Journal, 18 (4), 213-225.

[18] Minkina, W., Dudzik, S. (2009). Infrared Thermography: Errors and Uncertainties. Wiley, 129. ISBN 978-0-470-68224-1.

[19] Dziarski, K., Hulewicz, A. (2021). Components of the uncertainty of thermography temperature measurements with the use of a macro lens. In 13th International Conference on Measurement. IEEE, 155158.

[20] Dziarski, K., Hulewicz, A., Dombek, G., Frąckowiak, R., Wiczynski, G. (2020). Unsharpness of thermograms in thermography diagnostics of electronic elements. Electronics, 9 (6), 897-1002.
[21] FLIR Systems. FLIR E-Series. www.globaltestsupply.com/pdfs/cache/www.globaltest supply.com/flir_systems/thermal_imager/e50/datashee t/flir_systems_e50 thermal_imager_datasheet.pdf.

[22] FLIR Systems. Close-up $2 x$ lens. www.flircameras.com/t197214-close-up-2x-lens.htm.

[23] Linear Motion Rail. (www.ebay.com)

[24] Krawiec, P., Rózanski, L., Czarnecka-Komorowska, D., Wargula, L. (2020). Evaluation of the thermal stability and surface characteristics of thermoplastic polyurethane V-belt. Materials, 13 (7), 1502-1520.

[25] Siemens. PLC Controller. https://docs.rsonline.com/4ed5/0900766b81397276.pdf.

[26] Tran, Q.H., Han, D., Kang, C., Haldar, A., Huh, J. (2017). Effects of ambient temperature and relative humidity on subsurface defect detection in concrete structures by active thermal imaging. Sensors, 17, 1718.

[27] Minkina, W., Klecha, D. (2015). Modeling of atmospheric transmission coefficient. In Proceedings of the Sensor 2015 and IRS2 2015 AMA Conferences, Nürnberg, Germany, 19-21.

[28] European co-operation for Accreditation. http://www.european-accreditation.org.

[29] Papadakos, G., Marinakis, V., Konstas, C., Doukas, H., Papadopoulos, A. (2021). Managing the uncertainty of the U-value measurement using an auxiliary set along with a thermal camera. Energy Build, 242, 110984.

[30] Kuwalek, P., Otomanski, P., Wandachowicz, K. (2020). Influence of the phenomenon of spectrum leakage on the evaluation process of metrological properties of power quality analyser. Energies, 13 (20), 5338-5355. 